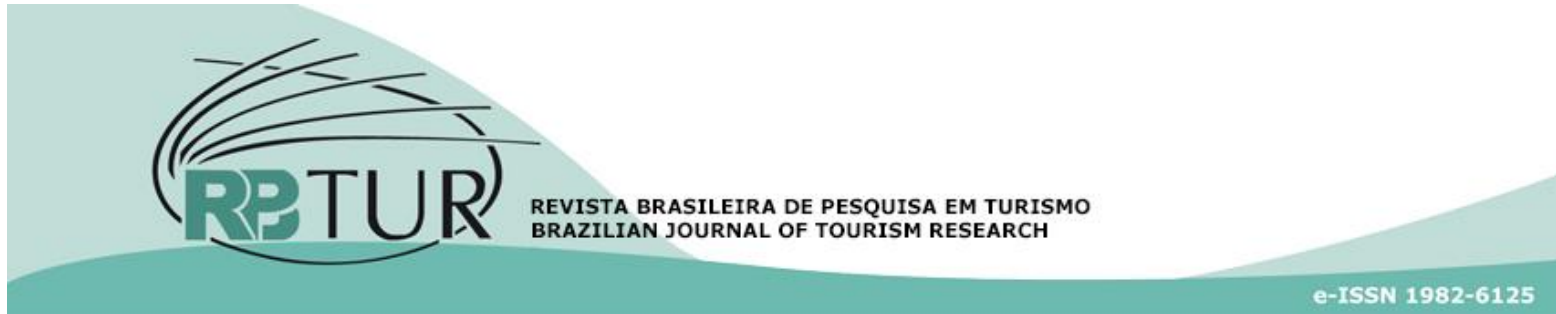

Artigos

\title{
Lazer, turismo, especulação imobiliária e conflito territorial entre São Miguel do Gostoso e Touros (RN)
}

\author{
Leisure, tourism, real estate speculation and territorial conflict between \\ São Miguel do Gostoso and Touros (RN)
}
Lazer, turismo, especulación inmobiliaria y conflicto territorial entre São Miguel do Gostoso y Touros (RN)

\section{Wagner Fernandes Costa ${ }^{1}$; Maria Aparecida Pontes da Fonseca ${ }^{1}$}

1Universidade Federal do Rio Grande do Norte (UFRN), Natal, Rio Grande do Norte, Brasil.

\section{Palavras-chave:}

Investimentos Turísticos; Mercado Imobiliário;

Conflito Territorial;

São Miguel do Gostoso.
Keywords:

Tourism Investments;

Real estate market;

Territorial Conflict;

São Miguel do Gostoso.
Resumo

$\mathrm{O}$ artigo analisa a relação entre o conflito territorial envolvendo os municípios de Touros e São Miguel do Gostoso (RN) e os investimentos turísticos e imobiliários. O conflito ocorreu após a revelação de um equívoco na demarcação das fronteiras entre esses municípios, quando São Miguel do Gostoso despontava como uma destinação turística. O incremento desses investimentos em toda Região Nordeste foi decorrente da transferência de capitais europeus em busca de valorização. A coleta de dados ocorreu através da consulta de documentos, da observação sistemática, entrevistas semiestruturadas e levantamento de dados cartoriais. Com o domínio territorial questionado, São Miguel do Gostoso acumulou ônus orçamentário devido a diminuição de repasses e tributos relacionados à contagem populacional e ao uso do solo urbano. Por outro lado, assumiu o encargo de prestar serviços públicos a residentes e turistas. Os investimentos tornaram-se indutores da expansão urbana, principalmente, na Ponta do Santo Cristo, área de maior disputa e expansão de investimentos imobiliários com destacada participação de estrangeiros. Assim, os investimentos ocorridos foram decisivos para desencadear o litígio, para o qual, o termo de um acordo entre os gestores foi condicionado à manutenção das terras da Praia da Ponta do Santo Cristo para Touros.

\section{Abstract}

The paper analyzes the relation between the territorial conflict involving the municipalities of Touros and São Miguel do Gostoso (RN) and tourist and real estate investments. This conflict occurred after the discovery of a mistake in the demarcation of the boundaries between the two municipalities, when São Miguel do Gostoso emerged as a tourist destination. The increase in such investments throughout the Northeast Region was due to the transfer of European funds in search of appreciation. In this study, the collection of data occurred through the consultation of documents, systematic observation, semi-structured interviews and survey of data from the registry. With the territorial domain questioned, it is verified that São Miguel do Gostoso started to accumulate budgetary burden due to the decrease of onlays and taxes related to the population count and the use of urban land. On the other hand, it assumed the responsibility of providing public services to residents and tourists. Investments became an incentive for urban expansion, mainly, Ponta do Santo Cristo, an 
Palavras clave:

Inversiones turísticas; Mercado inmobiliario; Conflicto Territorial; San Miguel do Gostoso.

Revisado por pares. Recebido em: 20/12/2018. Aprovado em: 21/01/2019.

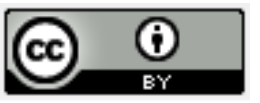

area of greater dispute and expansion of real estate investments with a significant partici pation of foreigners. It is concluded that the investments occurred were decisive to trigger the litigation, for which, the termination of an agreement between the managers was conditioned to the maintenance of the lands of Ponta do Santo Cristo Beach for Touros.

Resumen

El trabajo analiza la relación entre el conflicto territorial involucrando a los municipios de Touros y São Miguel do Gostoso (RN) y las inversiones turísticas e inmobiliarias. El referido conflicto ocurrió después de ocurrir la revelación de un error en la demarcación de las fronteras entre los dos municipios, cuando San Miguel do Gostoso surgía como un destino turístico. El incremento de tales inversiones en toda la Región Nordeste fue consecuencia de la transferencia de capitales europeos en busca de valorización. En este estudio, la recolección de datos ocurrió a través de la consulta de documentos, de la observación sistemática, entrevistas semiestructuradas y levantamiento de datos em la oficina de notários. Con el dominio territorial cuestionado, se constata que São Miguel do Gostoso pasó a acumular una carga presupuestaria en función de la disminución de transferencias y tributos relacionados con el conteo poblacional y el uso del suelo urbano. Por otro lado, asumió el cargo de prestar servicios públicos a residentes y turistas. Las inversiones se convirtieron en inductores de la expansión urbana, principalmente en Ponta de Santo Cristo, área de mayor disputa y expansión de inversiones inmobiliarias con destacada participación de extranjeros. Se concluye que las inversiones ocurridas fueron decisivas para desencadenar el litigio, para el cual, el término de un acuerdo entre los gestores fue condicionado al mantenimiento de las tierras de la Playa de Ponta do Santo Cristo para Toros.

Como citar: Costa, W. F. L.; Fonseca, M. A. P. (2019). Lazer, turismo, especulação imobiliária e conflito territorial entre São Miguel do Gostoso e Touros (RN). Revista Brasileira de Pesquisa em Turismo, São Paulo, 13 (3), p. 92-104, set./dez. http://dx.doi.org/10.7784/rbtur.v13i3.1587

\section{INTRODUÇÃO}

Inserir-se na economia global exige dos países, regiões, cidades e territórios a constituição de um espaço adequado para as atividades produtivas. Afinal, a capacidade dos lugares em responder aos investimentos varia pelas condições de ordem técnicas e organizacionais criadas para cada produção (Santos, 2009).

Seguindo essa premissa, a efetivação do Programa de Desenvolvimento do Turismo (PRODETUR) e das ações previstas pelo Programa de Aceleração do Crescimento (PAC), refletem os compromissos da agenda Neoliberal assumidos pelo Estado na reestruturação do Nordeste brasileiro com vistas ao estímulo do turismo. No Rio Grande do Norte, tais investimentos resultaram no aumento do fluxo de turistas nacionais e internacionais e na expansão do turismo a partir de Natal, capital do Rio Grande do Norte.

Com a soma de esforços entre a iniciativa pública e privada, municípios litorâneos tornaram-se localidades turísticas, constituindo-se novas destinações, tais como Tibau do Sul, cujo crescimento ocorre de forma significativa a partir dos anos de 1990, e São Miguel do Gostoso que desponta a partir de 2000. Associado à atividade turística, verifica-se um incremento de investimentos no setor imobiliário envolvendo atração de capitais procedentes, principalmente, de países europeus, mas também de outros continentes. Tratava-se de uma dinâmica que garantia a acumulação através do consumo do lazer e do turismo ou, unicamente, por ações especulativas na periferia da economia globalizada.

A relação entre o turismo e o setor imobiliário avança em países desenvolvidos e em desenvolvimento (Gonzáles \& Mantecón, 2014, Fonseca \& Janoschka, 2018), decorrentes de motivações financeiras e socioculturais (Palafox-Muñoz, Dizb-Basto \& Kauil-Fernández, 2014; Benson \& O'reilly, 2009), contando com forte apoio da administração pública para atrair investimentos estrangeiros (Gomes, Pinto \& Almeida, 2017).

O aquecimento do mercado imobiliário associado à atividade turística no mediterrâneo europeu, especialmente no litoral espanhol (Mantecón, Huete \& Mazón, 2009; Huete \& Mantecón, 2010, 2013), se difunde para o Nordeste brasileiro a partir de 2000, conforme analisado por Dantas, Clementino e Ferreira (2010). No Rio Grande do Norte, destaca-se o trabalho organizado por Fonseca (2012), na análise desse processo, além de outros estudos em contextos municipais (Assis, 2012; Novaes, 2012; Toniolli, 2014; Nunes, 2014; Santos Junior, 2015). 
No ano de 2010, ainda sobre os reflexos de intensa transferência de capitais estrangeiros para o setor imobiliário, os municípios de Miguel do Gostoso e Touros, ambos situados na porção leste do litoral do Rio Grande do Norte (Figura 1), passaram a divergir sobre os limites instituídos no momento de emancipação de São Miguel do Gostoso, desmembrado de Touros em 1993. Um equívoco no processo demarcatório, que foi revelado após o último censo populacional (2010), avançou para um conflito territorial, marcado por tentativas de revisão dos limites municipais, cobrança dupla de impostos, diminuição de transferências de recursos da União e articulações políticas cujos efeitos negativos sobre a gestão do território incidiam, prioritariamente, em São Miguel do Gostoso, como identificado por Costa (2018).

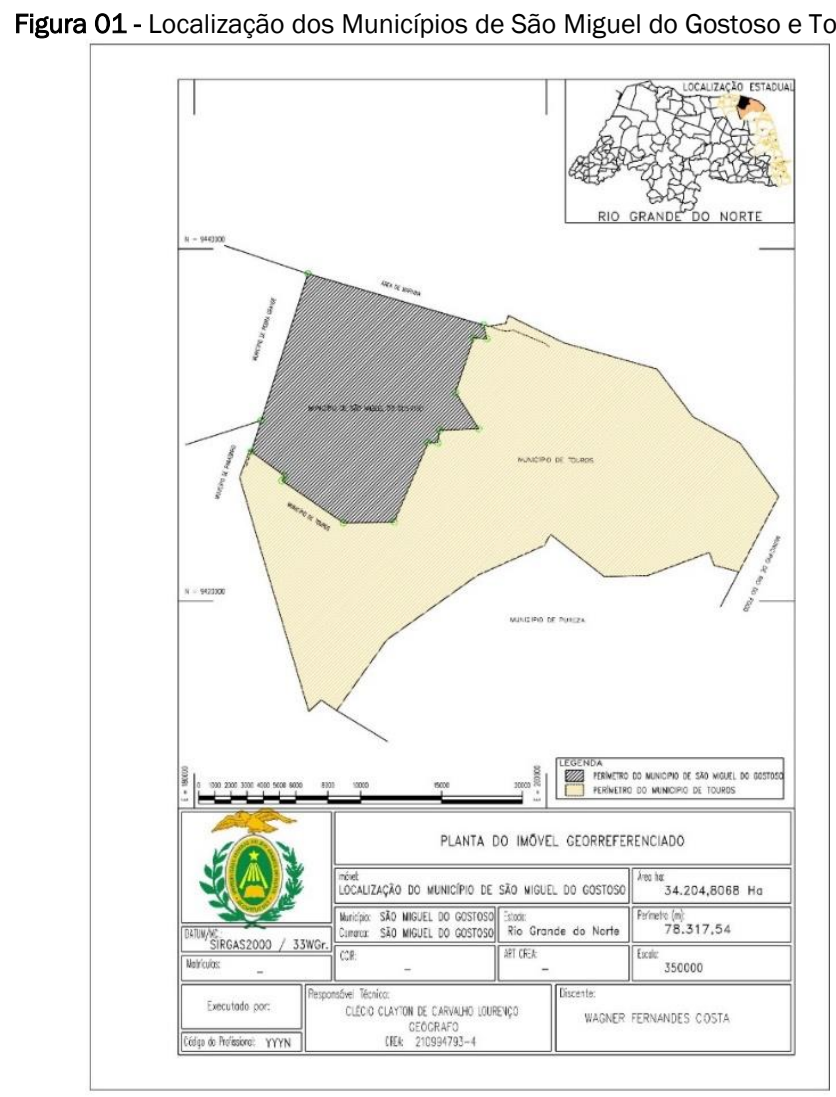

Fonte: Dados da Pesquisa, 2017.

Diante do exposto, o objetivo deste artigo é analisar a relação entre o conflito territorial envolvendo São Miguel do Gostoso e Touros e o processo de expansão do turismo e dos investimentos imobiliários nos municípios em questão.

Para o desenvolvimento do estudo, parte-se do pressuposto de que as transformações ocorridas no litoral do Rio Grande do Norte, estão relacionadas ao movimento dinâmico do capital que encontra no fluxo turístico e no setor imobiliário condições satisfatórias de migração entre os circuitos e territórios que garantem a sua reprodução (Harvey, 2004). Os investimentos acarretaram a valorização do solo e despertaram o interesse do Estado para a absorção dos impostos e dinamização da economia local-regional.

A compreensão do litígio, foco deste trabalho, requer um olhar para as novas dinâmicas territoriais relacionadas ao aquecimento dos investimentos imobiliários, prioritariamente destinados à uma demanda estrangeira e voltados às atividades de lazer, turismo e migração na região, particularmente em São Miguel do Gostoso, uma destinação turística em ascensão no Rio Grande do Norte. Ademais, esclarecer a origem, a natureza e as consequências do litígio tornava-se uma motivação fundamental em função de suas implicações na vida cotidiana da população local. 
0 texto está dividido em cinco seções. No primeiro momento são explicitados os procedimentos metodológicos adotados na pesquisa. Em seguida são apresentados os elementos que caracterizam o conflito entre os municípios. Após, são discutidos os mecanismos de reprodução capitalista que associam o turismo ao setor imobiliário. A quarta seção apresenta os dados dos investimentos turísticos e imobiliários em São Miguel do Gostoso e Touros. Finalmente, na última seção, são analisadas as condições e implicações para um acordo entre as municipalidades.

\section{PROCEDIMENTOS METODOLÓGICOS}

Para execução da pesquisa foi necessário um exaustivo levantamento documental, envolvendo um conjunto de leis, relatórios técnicos, registro cartográfico e comunicações institucionais, relativos à emancipação, à demarcação e às tentativas de revisão dos limites territoriais. Tais documentos subsidiaram a identificação de fatores que envolveram a incongruência territorial, bem como os caminhos percorridos para a solução do problema, decorrentes do litígio entre os municípios.

Os documentos cartoriais forneceram a base para analisar os investimentos imobiliários realizados. Foram consultadas as fichas de imóveis contendo transações realizadas a partir do ano 2000 , quando os investimentos internacionais se intensificam no litoral potiguar, difundindo-se para os municípios ao norte de Natal. Outro critério de seleção amostral foi definido pela presença de estrangeiros nas transações imobiliárias, comprando ou vendendo imóveis. Optou-se por esse perfil por considerá-lo como um dos principais responsáveis pela ordenação espacial, através dos investimentos turístico-imobiliários. A amostra de 289 transações foi reveladora da localização, característica, magnitude, origem e o período dos investimentos transacionados nos municípios, elementos que caracterizam a produção imobiliária e o processo de valorização de terras em Touros e São Miguel do Gostoso.

No que concerne à pesquisa de campo, optou-se pela observação sistemática, com o uso de instrumento de registro de informações da oferta turística. Foram visitados 190 empreendimentos de prestação de serviços turísticos, sendo 162 em São Miguel do Gostoso e 28 em Touros. A expectativa é ter catalogado todo o universo em questão.

Para completar o levantamento, foram realizadas 24 (vinte e quatro) entrevistas individuais e semiestruturadas em uma amostra selecionada de forma gradual (Flick, 2004) que envolveu os seguintes agentes: lideranças do processo de emancipação, gestores públicos (prefeitos, vereadores e secretários), empresários do segmento turístico e imobiliário, representantes comunitários (igrejas, associações, conselhos, sindicatos, ONGs), políticos e técnicos envolvidos com os eventos de demarcação e busca por solução do impasse. Considerando-se que a população se apresenta de forma extremamente heterogênea e dispersa em vários grupos de interesse, o discurso de tais agentes sintetiza as questões que envolvem o conflito territorial analisado.

Os dados e informações levantadas permitiram produzir inferências sobre a importância do turismo e da atividade imobiliária nos dois municípios e como os variados subgrupos percebiam tais atividades perante o conflito.

\section{O TERRITÓRIO EM QUESTÃO: A NARRATIVA DE UM CONFLITO}

Em 1993 São Miguel do Gostoso emancipou-se de Touros num contexto de reivindicações dos grupos organizados (igreja, professores, políticos) do então vilarejo. A promulgação da Lei $n^{\circ} 6.452$ finalizou o processo emancipatório, criando o Município e demarcando seus limites. Porém, em 2010, a contagem populacional feita pelo censo do Instituto Brasileiro de Geografia e Estatística (IBGE) revelou que o perímetro municipal de São Miguel do Gostoso não foi definido de acordo com as expectativas do projeto emancipatório. Mantendo-se a demarcação prevista na lei, parte de sua sede e de povoados rurais estavam, na verdade, englobados nos domínios territoriais de Touros. Um erro que a população desconhecia e que a partir de sua evidenciação passou a gerar dificuldades para a gestão do território.

Um dos problemas se refere à diminuição de repasses federais que se baseiam na contagem populacional efetivada pelo IBGE. Em 2010, por não atribuir à São Miguel do Gostoso a população residente na área de 
litígio, houve um ônus orçamentário de $\mathrm{R} \$ 400$ (quatrocentos) mil reais/mês somente no Fundo de Participação dos Municípios (FPM). Acrescente-se ainda, outros recursos que tem como base o coeficiente populacional, tal como a repartição de Fundos ligados à educação e à saúde pública.

O uso do território tornou-se mais complexo em função da expansão urbana ocorrida nos últimos anos em direção à área de litígio. Dentre as edificações encontradas na área, havia dezoito órgãos públicos municipais que efetivamente prestavam serviços à população local e eram mantidos por São Miguel do Gostoso.

Os problemas com a arrecadação de impostos sobre os serviços prestados (ISS), sobre o uso do solo urbano (IPTU) e sobre as transferências de propriedade de imóveis (ITIV) na área de litígio evidenciavam que um número significativo de munícipes não cumpria os compromissos tributários. Entre os gestores havia a compreensão que a inadimplência era fruto do impasse nos limites municipais, uma vez que, não definido qual municipalidade era, de fato, detentora do direito, os tributos não eram pagos a nenhum dos dois municípios.

A atividade turística agravou as dificuldades de gestão pública, uma vez que o setor empresarial, apesar de não cumprir com suas obrigações tributárias, exigia investimentos e obras públicas da municipalidade. Acrescente-se ainda que a demanda turística adiciona um contingente populacional que eleva a necessidade por serviços públicos.

Convictos da necessidade de correção dos limites territoriais para equilibrar a receita de São Miguel do Gostoso, seus gestores destinaram esforços para uma solução. Até o final de 2012 ocorreram sete reuniões entre prefeitos e técnicos de órgãos competentes para discutir a questão ${ }^{1}$. No entanto, frente as negativas dos políticos de Touros, a revisão não pôde ser firmada.

Com novas administrações municipais iniciadas em 2013, o quadro de impasse se aprofundou pela recusa dos gestores em comparecer às sessões técnicas para efetuar a revisão dos limites. Ocorreu também, por parte da administração pública de Touros, investidas para arrecadar impostos de empreendimentos turísticos em área de litígio. Tais fatos alertaram a gestão de São Miguel do Gostoso quanto a um provável fracasso no seu pleito a depender da anuência dos gestores de Touros. Com isso, buscou-se resolver o impasse de forma unilateral junto ao poder Legislativo do Rio Grande do Norte. Esta medida mostrou-se igualmente inócua devido a influência política de Touros na Assembleia Legislativa, de modo que o processo de revisão dos limites não avançou.

\section{A ORDENAÇÃO DO TERRITÓRIO A PARTIR DA RESOLUÇÃO ESPAÇO-TEMPORAL DO CAPITAL}

Uma das contribuições da produção acadêmica do geógrafo inglês David Harvey é a busca por esclarecer a dinâmica do capital a partir do conceito de "ordenação espacial". Segundo o autor, desde a década de 1970, as tendências de crises capitalistas são enfrentadas através da transferência de capital entre circuitos econômicos e territórios que possibilitam melhores condições de rentabilidade (Harvey, 1989, 2008). Nesse período, as ações do Estado neoliberal têm ocorrido para ampliar a arena de ação do setor privado (Harvey, 2004). Esses são os marcos teóricos e conceituais que fundamenta a presente discussão.

A “ordenação espacial” (Harvey, 2011), ou a "resolução espacial" (Valença, 2008), como também é adotado no Brasil, é um movimento duplo. Por um lado, ocorre a alocação de capitais e trabalho (embora o primeiro seja prioritário) para a produção de mercadorias em outros territórios, chamado de deslocamento espacial. De outro lado, ocorre a transferência do capital para atividades de rentabilidades de médio ou longo prazo, através de infraestruturas físicas e sociais, chamado de deslocamento temporal. Considerando que para resolver o problema de absorção de capitais é mais eficaz uma combinação entre as duas possibilidades, Harvey (2011, p. 78) também passa a chamar o resultado de tais movimentos de "ordenações espaçotemporais".

\footnotetext{
${ }^{1}$ As ações iniciais contaram com o apoio do IBGE e da Secretaria de Estado de Assuntos Fundiários e Apoio a Reforma Agrária do Rio Grande do Norte (SEARA/RN). Em geral, uma revisão de limites é feita através de um acordo firmado pelos chefes do executivo municipal a partir de um consenso que contemple os interesses de ambos.
} 
Dessa forma, o principal circuito de reprodução do capital (industrial) perde importância em relação aos outros segmentos econômicos que assumem primazia no processo de reprodução do capital. É dessa forma que os mecanismos de transferência de capitais para territórios carentes de infraestrutura adquirem relevância por manter graus variáveis de estabilidade ao capitalismo.

O Estado, por sua vez, é um agente fundamental na dinâmica do capitalismo global (Harvey, 2008). Por isso, na consolidação da sinergia Estado-Capital, as políticas públicas foram fundamentais para lastrear a ordenação espaço-temporal ocorridos na região Nordeste brasileira e, particularmente, no território potiguar. Tal fato ocorre alinhado à agenda de compromissos Neoliberais, onde cabe ao Estado prover as condições que facilitem a mobilidade do capital, superando barreiras ou entraves que comprometem sua reprodução.

Nesse sentido, o litoral nordestino foi estruturado para o turismo com a efetivação do Programa de Desenvolvimento do Turismo (PRODETUR/NE), que, dentre outras ações empreendidas pelo poder público, teve um papel fundamental para expansão do turismo regional (Cruz, 2000; Fonseca, 2005). No estado do Rio Grande do Norte foram aplicados mais de US $\$ 87$ (oitenta e sete) milhões nas duas fases do programa, contribuindo para maior acessibilidade e circulação dos visitantes no litoral potiguar, para além da Região Metropolitana de Natal, bem como para o crescimento do fluxo turístico internacional.

Entre os anos de 2011 e 2014, ocorreu a segunda edição do Programa de Aceleração do Crescimento (PAC2) cujos investimentos repercutiram de forma acentuada sobre o sistema de transporte do Rio Grande do Norte. Destaca-se o valor de R\$731,14 (setecentos e trinta e um) milhões para a construção do Aeroporto Internacional Governador Aluízio Alves, situado no município de São Gonçalo do Amarante (Comitê Gestor do PAC, 2014) que ampliou a capacidade de operações de passageiros e cargas para o estado, ao mesmo tempo em que, pela sua localização, passou a favorecer o deslocamento de visitantes para os municípios situados ao norte de Natal, como, por exemplo, São Miguel do Gostoso e Touros. Os acessos, a integração, as melhorias da infraestrutura e da qualidade de atrativos, entre outras medidas foram, portanto, fundamentais para dotar o sistema turístico potiguar de maior competitividade no cenário global.

Um dos resultados das intervenções estatais sobre o território potiguar foi a valorização de terras em municípios situados fora da Região Metropolitana pela possibilidade de receber capitais privados no segmento turístico e imobiliário. Muitos destes investimentos foram canalizados para o setor imobiliário vislumbrando uma oportunidade promissora de ganhos pela comercialização de imóveis destinados ao público externo, principalmente estrangeiro. São novas dinâmicas que incidem sobre o litoral Potiguar e mostram-se relevantes no município de Touros e São Miguel do Gostoso.

Os processos de migração temporal e espacial do capital, com ativa participação do Estado, têm gerado quadros contraditórios. Apesar de Harvey estabelecer sua teoria no contexto dos Estados Nacionais é possível fazer correlações com o cenário do conflito territorial aqui analisado, uma vez que, resguardadas as devidas proporções, o princípio se mantém: o poder público (independentemente da unidade administrativa correspondente) busca ser o arcabouço político-territorial por onde ocorrem os processos de circulação e reprodução do capital, gerando, em muitos casos, tensões na relação inter Estados, induzindo a práticas imperialistas, desenvolvendo conflitos geopolíticos (Harvey, 2004).

Além das motivações econômicas, conforme descrito acima, tais investimentos turísticos-imobiliários também são motivados por transformações de ordem socioculturais (valores e estilos de vida) e técnicas (meio de transportes e comunicações) que tem acarretado o crescimento das migrações por amenidades nas áreas litorâneas com temperaturas mais elevadas (Benson \& O'reilly, 2009; Huete \& Mantecón, 2010, 2013).

\section{O TURISMO, LAZER E PRODUÇÃO IMOBILIÁRIA EM SÃO MIGUEL DO GOSTOSO E TOUROS (RN)}

O interesse do Estado nacional em participar do mercado turístico internacional exige que o planejamento contemple as necessidades estruturantes do setor (Hall, 2001). Com efeito, as unidades territoriais que melhor desempenham tal esforço adquirem o rótulo de destino turístico (Valls, 2006). Com isso, o crescimento dos investimentos em infraestruturas para turismo sobre novos territórios se torna exemplo emblemático da Ordenação Espacial. 
Nos destinos turísticos, o espaço adquire outras configurações provenientes dos investimentos imobiliários com o objetivo de auferir lucros com uma posterior negociação em função das baixas taxas financeiras e das margens elevadas de lucros comparados outros setores, ou seja, fins especulativos (Gaja i Díaz, 2008, 2013).

A análise dos investimentos turísticos e imobiliários nos municípios foco deste estudo revela o esforço das diversas esferas de governo na implantação de medidas estruturantes para consolidar o turismo, ocasionando transformações socioespaciais. Ao mesmo tempo, induzem a ocupação de novas áreas litorâneas com participação de investimentos internacionais na aquisição de terras e imóveis destinados à segunda residência, por vezes associadas a empreendimentos turísticos.

\subsection{Investimentos Turísticos em São Miguel do Gostoso e Touros}

Em São Miguel do Gostoso, a configuração de um destino turístico é uma realidade. Segundo a classificação do Ministério do Turismo, o município possui a categoria B, o que aponta uma boa posição na competitividade turística no contexto regional. A atividade turística contou com ações do poder público na implantação de infraestrutura, bem como de investimentos privados no que se refere à implantação de equipamentos de hospedagem, alimentação e agenciamento. Destaca-se o segmento de esportes náuticos e lazer na praia, com acentuada participação de estrangeiros. No Gráfico 1 é possível verificar a evolução da abertura de empreendimentos turísticos em São Miguel do Gostoso entre o ano 2000 e janeiro de 2017.

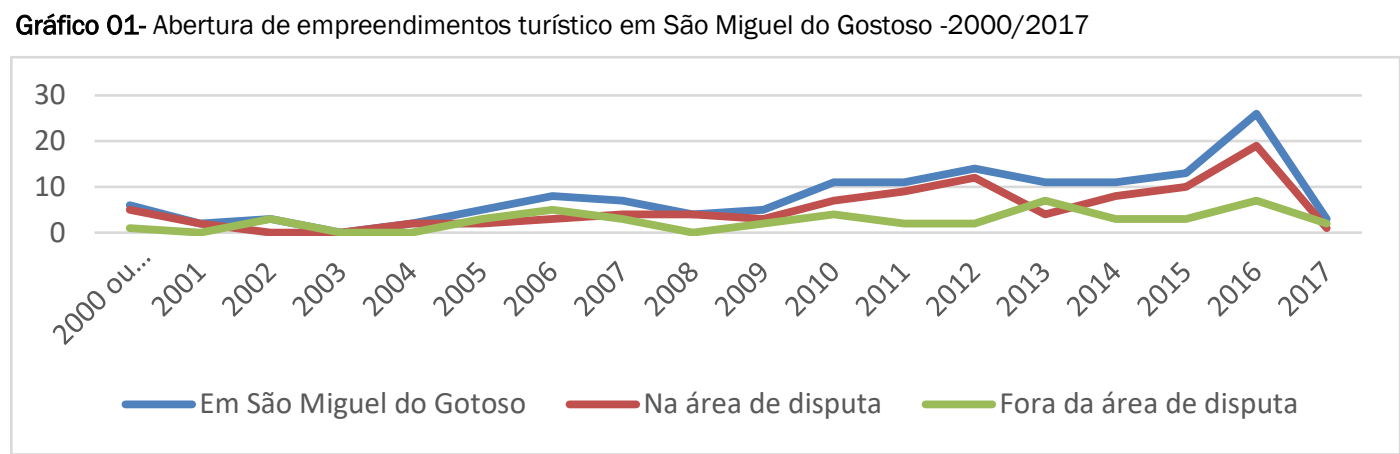

Fonte: Dados da Pesquisa, 2017.

Estudos anteriores constatam a importância do aporte de capitais internacionais nas atividades ligadas ao turismo local (Taveira, 2015), ocasionando a apropriação do território pela e para tal atividade. A refuncionalização turística gerou complexas alterações na dinâmica sociocultural do município (Matias \& Carvalho, 2017).

Os convênios firmados entre o município e o Ministério do Turismo para captação dos recursos, demonstram a articulação das diversas esferas de Estado para a consolidação de um ambiente propício à atividade. Dos valores investidos em melhorias para o turismo $(\mathrm{R} \$ 3.822 .088,73)$, a maior parte $(\mathrm{R} \$ 2.756 .519,67)$ têm sido aplicados em obras de urbanização, prioritariamente na Avenida dos Arrecifes, que se constitui o principal eixo de circulação da cidade. A concentração dos investimentos públicos acentuou a urbanização ao longo desse logradouro, exatamente no sentido da RN 221, que dá acesso à Touros. As melhores condições de infraestrutura urbana também definem a preferência locacional dos empreendimentos turísticos que se instalam ao longo desta avenida. Das 163 empresas de serviços turísticos identificadas em São Miguel do Gostoso, 65 estão situadas ao longo desse logradouro, ou seja, 40\% do total.

Verifica-se ainda que as praias de Xepa, Cardeiro e Santo Cristo (sendo este último bairro a principal área questionada no litígio territorial entre São Miguel do Gostoso e Touros) englobam 105 empreendimentos de prestadores de serviços turísticos, representando 63\% do total (ver Gráfico 1). Desta forma, a seletividade espacial de tais investimentos indica a participação do turismo no ordenamento territorial, direcionando o crescimento urbano, bem como a constituição de uma coesão territorial (Corrêa, 1997) que extrapolou os limites impostos pela demarcação atribuída ao município de São Miguel do Gostoso. 
Ao contrário de São Miguel do Gostoso, no Município de Touros, o poder público e a iniciativa privada não estiveram imbuídos no desenvolvimento da atividade turística nos últimos anos e, portanto, não tem sido um vetor de transformação do espaço ou de crescimento econômico no município. As fragilidades na infraestrutura urbana e os parcos esforços para ações estruturais e institucionais são dificuldades reconhecidas pelos gestores públicos e empresários. Em função disso, muitos empreendedores se valem da proximidade com São Miguel do Gostoso para suas ações promocionais, definindo-se como sendo integrante da oferta turística desse município.

Em 2017, no entanto, a construção de um resort com 514 unidades habitacionais pelo grupo português Vila Gallé, com investimento de $\mathrm{R} \$ 150$ milhões de reais e previsão de geração de 400 empregos diretos, reativa o interesse dos gestores municipais de Touros em garantir as condições que o ajuste espacial exige. A expectativa em torno desse empreendimento mobilizou o poder público para a criação de infraestrutura de acesso, capacitação de mão de obra e isenção fiscal, isto é, providências que seguem a linha da responsabilidade do Estado na agenda neoliberal. Em contrapartida o poder público local tinha a expectativa de que o resort possibilitasse o aumento do fluxo turístico internacional no município, a geração de empregos e o incremento na arrecadação.

\subsection{Investimentos Imobiliários em São Miguel do Gostoso e Touros}

O número de transações imobiliárias envolvendo estrangeiros apresentou significativo crescimento em São Miguel do Gostoso entre os anos de 2002 e 2008. Já Touros teve um aquecimento do mercado imobiliário mais breve, compreendido entre os anos 2002 e 2005. Os efeitos da crise econômica de 2007/2008 se fez sentir localmente em ambos os municípios, verificando-se o declínio das transações imobiliárias. Apesar deste desaquecimento, os negócios em São Miguel do Gostoso apresentarem-se mais distribuídos ao longo dos anos, mantendo também a superioridade de valores investidos no período analisado (Gráfico 2).

As tipologias de imóveis apresentam diferenças significativas. Em São Miguel do Gostoso predominou o mercado de terras ( $97 \%$ das transações) em forma de lotes ou terrenos. Já em Touros, as transações envolvendo casas e chalés é a tipologia mais comercializada (49\% das transações), seguido pelo mercado de terras (46\%).

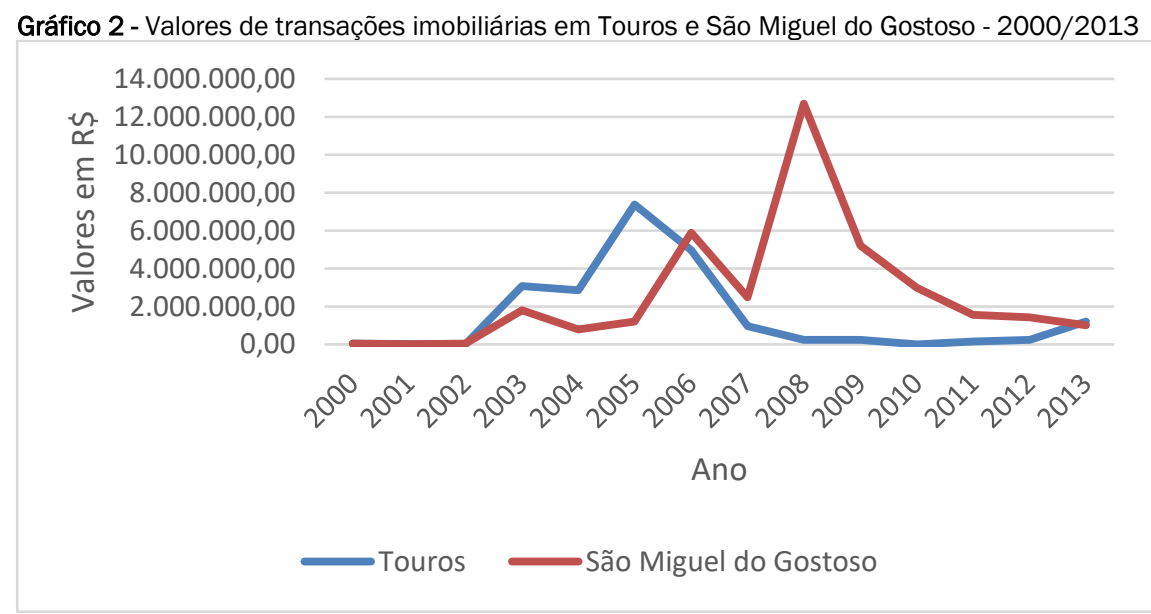

Fonte: Cartório de Imóveis de Touros, 2016.

Considerando que praticamente não foram identificadas transações envolvendo metro quadrado construído em São Miguel do Gostoso, optou-se por realizar uma comparação entre os preços das terras situadas na faixa litorânea. Analisando-se os dados do Gráfico 3, percebe-se que a partir de 2003 há um distanciamento dos valores praticados nos dois municípios. Em 2005 foram concluídas uma série de melhorias na Sede municipal e a partir de 2010 inicia a primeira etapa das obras de urbanização da Avenida dos Arrecifes. Os 
investimentos públicos agregaram valor ao solo, repercutindo sobre o mercado imobiliário local. Após 2011, o preço do metro quadrado em São Miguel do Gostoso chegou a custar o triplo em relação à Touros.

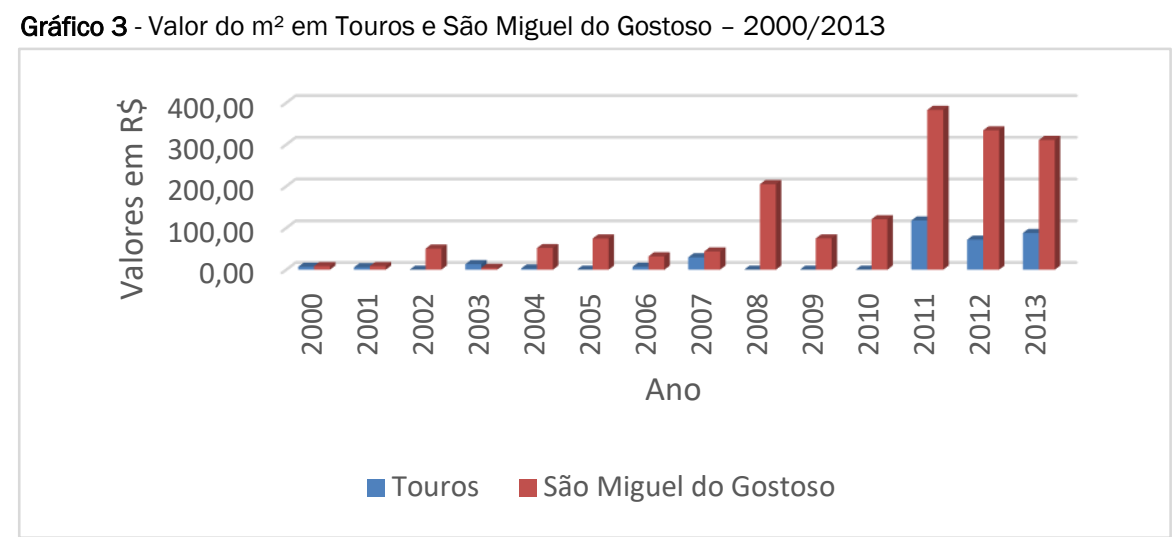

Fonte: Cartório de Imóveis de Touros, 2016.

Se constata a primazia de investidores de origem europeia em ambos os municípios, dentre os quais destacam-se os ibéricos (espanhóis e portugueses). A análise da participação da demanda internacional nas transações, especialmente em São Miguel do Gostoso, revela que ao longo dos 13 anos os estrangeiros passaram de compradores à vendedores de imóveis, especialmente após 2008. São transações que contaram com estrangeiros enquanto intermediários, aproveitando-se de aumentos do preço do solo (houve casos de aumento de $325 \%$ por ano) em pleno ápice do fluxo de capitais no município.

As ações de infraestrutura urbana desenvolvidas pelo poder público fomentaram a expansão da atividade turística em São Miguel do Gostoso. Associado ao crescimento do turismo, ocorreu um processo de expansão imobiliária com investimentos que se beneficiavam da disponibilidade de terras com preços muito inferiores comparativamente ao mercado europeu. À medida que se verificava o crescimento do turismo, as praias do município passaram a se valorizar diante da procura por novas áreas de expansão imobiliária. Um movimento articulado que gerou acentuada ocupação e valorização das terras situadas, principalmente, nas praias da Xepa, Cardeiro e Santo Cristo.

\section{AS AÇÕES E OS OBJETOS PARA A SOLUÇÃO DO CONFLITO TERRITORIAL}

Em decorrência dos investimentos descritos, São Miguel do Gostoso passou de um vilarejo habitado prioritariamente por pescadores e agricultores à uma das mais importantes destinações turísticas do estado do Rio Grande do Norte. As fontes de pesquisa atribuíram à essa condição assumida pelo município, o impasse que se estabeleceu com o município de Touros.

0 interesse dos administradores municipais envolvia, mais especificamente, as terras urbanas. Nessas, o solo adquire valor distinto por concentrar os investimentos. Os empreendimentos já instalados e as perspectivas de novos negócios tornaram as praias da Xepa, Cardeiro e principalmente Santo Cristo, espaços diferenciados no território de São Miguel do Gostoso.

Existem recorrentes referências à Praia de Ponta do Santo Cristo enquanto local de concentração de empreendimentos imobiliários e turísticos. Esta área tornou-se mais valorizada em função das amenidades naturais e infraestrutura urbanística, elementos que incidem sobre o preço do metro quadrado. Esta localidade (e suas imediações) se destacou frente às demais, enquanto lócus prioritário de investimentos estrangeiros.

A municipalidade de Touros reconhecia que as terras em litígio eram as mais valorizadas, bem como, existia a consciência de vício na demarcação que Ihe atribuía o domínio das praias da Xepa e Cardeiro. No entanto, a mesma condescendência não era demonstrada em relação à Praia da Ponta do Santo Cristo, onde se expressava o interesse em manter o domínio territorial.

Buscando conciliar o interesse de Touros, foi estabelecido um recuo no limite Leste do Município, em relação ao que foi idealizado pelo movimento emancipatório, onde a Praia da Ponta do Santo Cristo estaria 
inteiramente situada em São Miguel do Gostoso. Com o referido recuo, parte desta Praia passa a pertencer a Touros (Figura 2).

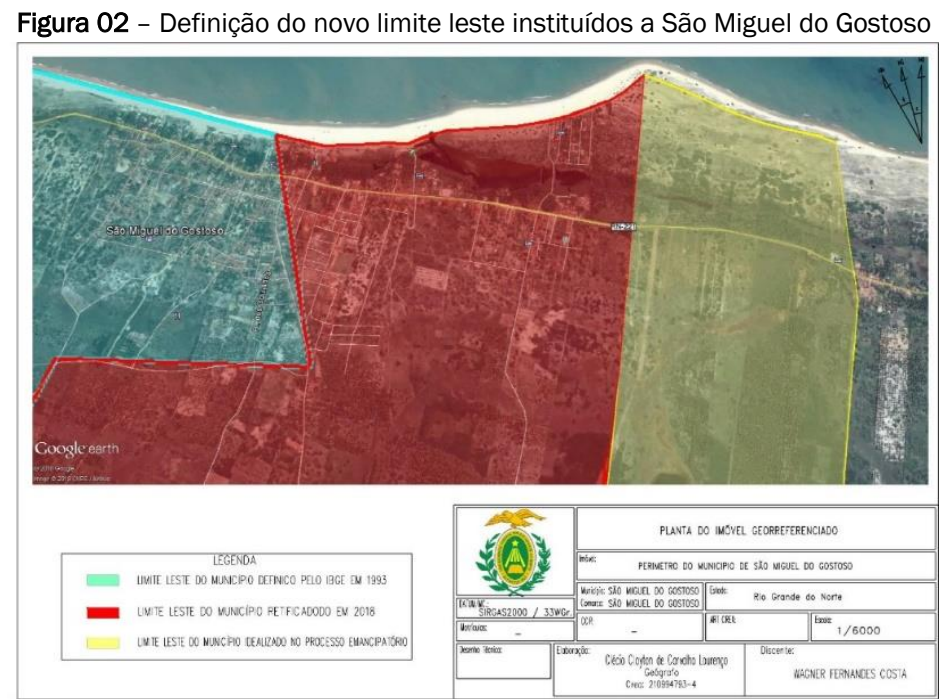

Fonte: Dados da Pesquisa, 2018

Com o sinal positivo da gestão de Touros o acordo pactuado foi encaminhado aos órgãos competentes para um novo processo demarcatório. Assim, em 02 de janeiro de 2018, foi sancionada pela Assembleia Legislativa do Rio Grande do Norte a Lei 10.315/2018 com os novos limites instituídos aos municípios (Figura 03).

É possível perceber que a nova demarcação territorial incorporou à São Miguel do Gostoso áreas rurais que se encontravam anteriormente em Touros. Sobre essas áreas e comunidades não houve nenhuma manifestação de interesse por parte dos gestores e lideranças entrevistadas, sinalizando que a preocupação quanto à manutenção ou aquisição de domínios de ambos os municípios recaia sobre a Sede Urbana, com especial interesse na Praia do Santo Cristo e adjacências. 
Figura 03 - Perímetro do Município de São Miguel do Gostoso em 2018.

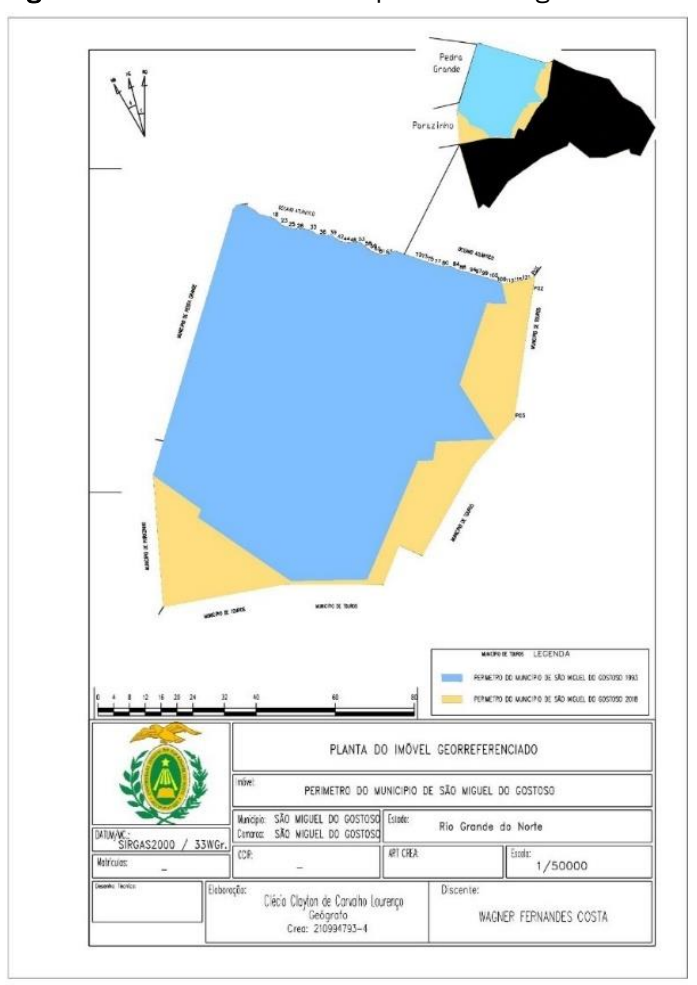

Fonte: Dados da Pesquisa, 2018

Vale destacar que a área litorânea objeto do acordo é alvo de sondagens para construção de empreendimentos turístico-imobiliários. A localização de empreendimentos turísticos e imobiliários nas proximidades de São Miguel do Gostoso, situados ao longo da RN 221 (de ligação entre os dois municípios), já rende aos empresários dos distritos de Touros algumas vantagens comparativas. Assim, a solução do conflito tem relação direta com as tendências locacionais prioritárias dos investimentos e a valorização que o solo adquiriu nos últimos anos.

\section{CONCLUSÕES}

As políticas públicas desenvolvidas no Nordeste possibilitaram maior integração e cooperação organizacional entre os processos econômicos no âmbito da esfera global e regional-local, oportunizando a valorização dos capitais excedentes, particularmente procedentes da Europa. Tais ações também contribuíram para incrementar o turismo e a produção imobiliária com interesses eminentemente especulativos que resultaram em crescente valorização do solo, uma vez que os capitais se configuraram como ativos incorporados a terra, no qual se buscavam extrair diversas formas de renda.

Este foi o cenário no qual São Miguel do Gostoso, uma destinação turística em ascensão, passou a divergir com o município vizinho, Touros, com relação aos limites territoriais de áreas rurais e urbanas. A questão adquiriu conotação de conflito a partir de negativas de correção das tentativas de revisão do equívoco na demarcação e das tentativas de cobranças de tributos por parte de Touros. A discussão girava em torno do domínio das praias da Xepa, do Cardeiro, e, principalmente, da Ponta do Santo Cristo, onde ocorreu um mecanismo sincrônico de geração de valor, envolvendo empreendedores de turismo, agentes imobiliários e o Estado.

Conclui-se que o litígio territorial entre Touros e São Miguel do Gostoso esteve relacionado ao incremento da atividade turística e a produção imobiliária efetivada no território desses municípios ao longo das últimas duas décadas. A solução do impasse reforça esta conclusão, uma vez que a condição estabelecida para um acordo foi que parcela da Praia da Ponta do Santo Cristo e adjacências, reivindicadas por São Miguel do Gostoso no processo emancipatório, se mantivessem sobre o domínio de Touros. 
Os resultados obtidos expressam que a transferência geográfica de capitais propiciou uma nova ordenação territorial nos municípios foco deste estudo, com a expansão da atividade turística em associação com o setor imobiliário. No modelo turístico sol e mar, a terra litorânea é um recurso escasso e elementar, por isso valorizam-se como mercadorias, acirrando a disputa entre agentes e entre lugares.

\section{REFERÊNCIAS}

Assis, L. F. (2012). Entre o turismo e o imobiliário: velhos e novos usos das segundas residências sob o enfoque da multiterritorialidade - Camocim/CE. Tese de Doutorado. Programa de Pós-Graduação em Geografia Humana. Faculdade de Filosofia, Letras e Ciências Humanas, Universidade de São Paulo, São Paulo.

Benson, M. \& O'reilly, K. (eds.) (2009). Lifestyle Migration. Expectations, Aspirations and Experiences. Farnham: Ashgate.

Comitê Gestor do PAC. (2014). $10^{\circ}$ Balanço - março/ junho. Disponível em: http://www.pac.gov.br/pub/up/pac/10/10PAC2-completo.pdf. Acesso em 25 de agosto de 2018.

Corrêa, R. L. (1997). Trajetórias geográficas. Rio de Janeiro: Bertrand Brasil.

Costa, W.F. (2008). Turismo, produção imobiliária e conflito territorial entre São Miguel do Gostoso e Touros $(R N)$. Dissertação de Mestrado. Programa de Pós-Graduação em Turismo. Centro de Ciências Sociais Aplicadas. Universidade Federal do Rio Grande do Norte, Natal.

Cruz, R.C. (2000). Política de turismo e território. São Paulo: Contexto.

Dantas, E. W.; Angela, A. L. \& Clementino, M. L. (2010). Turismo e imobiliário nas metrópoles. Rio de Janeiro: Letra Capital.

Flick, U. (2004). Introdução à pesquisa qualitativa. São Paulo: ARTMED.

Fonseca, M. A. (2012). Turismo, lazer e segunda residência. Natal: EDUFRN.

Fonseca, M. A. \& Janoschka, M. (2018). Turismo, mercado imobiliário e conflitos sócioespaciais no nordeste brasileiro. Sociedade e Território, Natal, 30(1), 51-67. https://doi.org/10.21680/2177-8396.2018v30n1

Gaja i Díaz, F. (2008). El "tsunami urbanizador" enel litoral mediterráneo. El ciclo de hiperproduccióninmobiliaria 1996-2006. Scripta Nova: revista electrónica de geografía y ciências sociales [enlínia], 12. Disponível em: https://raco.cat/index.php/ScriptaNova/article/view/115464. Acesso em 25 de agosto de 2018.

Gaja i Díaz, F. (2013). Trasel tsunami inmobiliario. Salir del atolladero. In: Observatorio metropolitano de Madri. Paisajes desvastados. Después del ciclo inmobiliario: Impactos regionales y urbanos de las crisis. Espanha: Traficantes de Sueños.

Gomes, R.; Pinto, E. \& Almeida C. (2017). Turismo residencial no Algarve: a percepção dos gestores do setor público. Revista Brasileira de Pesquisa em Turismo. São Paulo, 11(2), 197-217. https://doi.org/10.7784/rbtur.v11i2.1246

González, R. \& Mantecón, A. (2014). Turismo y negocio inmobiliario: lacrisis de un modelo de Desarrollo. Tres casos de estudio de Canada, Argentina y España. Estudios y Perspectivas en Turismo, 23(4).

Hall, M. (2011). Planejamento turístico: políticas, processos e relacionamentos. São Paulo: Cantexto.

Harvey, D. (1989). The Urban Experience. Oxford, UK: BasilBleckwell.

Harvey, D. (2004). O novo imperialismo (2 ed.) São Paulo: Loyola.

Harvey, D. (2008). O neoliberalismo: história e implicações. São Paulo: Edições Loyola.

Harvey, D. (2011). O enigma do capital: e as crises do capitalismo. São Paulo, SP: Boitempo.

Huete, R. \& Mantecón, A (2010). Los límites entre el turismo y la migración residencial. Una tipología. Papers. Revista de Sociología, 95(3), 781-801. http://dx.doi.org/10.5565/rev/papers/v95n3.95

Huete, R., \& Mantecón, A. (2013). La migración residencial de noreuropeos en España. Convergencia. Revista de Ciencias Sociales, 20(61), 219-245.

Mantecón, A.; Huete, R. \& Mazón T. (2009). Las urbanizaciones "europeas". Una investigación sobre las nuevas sociedades duales en el Mediterráneo. Scripta Nova. Revista Electrónica de Geografía y Ciencias Sociales. 3(301). Disponível em: http://www.ub.es/geocrit/sn/sn-301.htm 
Matias, E. \& Carvalho, A. (2017). Microrrealidades socioculturais transformadas pelo turismo em São Miguel do Gostoso, Rio Grande do Norte, Brasil. Revista Brasileira de Pesquisa em Turismo. São Paulo, 11(3), 537 557. https://doi.org/10.7784/rbtur.v11i3.1319

Novaes, L. N. S. (2012). Turismo de sol e mar: empreendimentos turísticos imobiliários e o desenvolvimento urbano e socioeconômico no litoral do Ceará - o caso de Beberibe. Tese de Doutorado. Programa de PósGraduação em Arquitetura e Urbanismo. Faculdade de Filosofia, Letras e Ciências Humanas, Universidade de São Paulo, São Paulo.

Nunes, M. R. O. (2014). Investimentos internacionais e o turismo em Tibau do Sul/RN. Dissertação de Mestrado. Programa de Pós-Graduação em Turismo. Centro de Ciências Humanas, Letras e Artes, Universidade Federal do Rio Grande do Norte, Natal.

Palafox-Muñoz, A., Dizb-Basto, A. \& Kauil-Fernandez, E. (2014). Una mirada al turismo residencial en la Isla de Cozumel, México. Revista Brasileira de Pesquisa em Turismo. São Paulo, 8(2), 326-339. http://dx.doi.org/10.7784/rbtur.v8i2.718

Santos Júnior, A. P. (2015) Investimentos internacionais e a valorização imobiliária dos municípios de Maxaranguape e Rio do Fogo. Dissertação de Mestrado. Programa de Pós-Graduação em Geografia. Centro de Ciências Humanas, Letras e Artes. Universidade Federal do Rio Grande do Norte, Natal.

Santos, M. (2009). A natureza do espaço: técnica e tempo, razão e emoção (4 ed.). São Paulo: EDUSP.

Taveira, M. S. (2015). A turistificação de São Miguel do Gostoso: a internacionalização da "cidade dos ventos". Revista Turismo e Desenvolvimento, 8(19).

Toniolli, L. S (2014). Uso e ocupação do trecho costeiro do Porto das Dunas: processo imobiliário, turístico e urbanístico. Dissertação de Mestrado. Mestrado em Desenvolvimento e Humanidades. Centro de Ciências, Universidade Federal do Ceará, Fortaleza.

Valença, M. (2008). Ensaio sobre a dinâmica do imobiliário em Harvey. In: Valença, M. (Org.). Cidade (i)legal. Rio de Janeiro: Mauad X.

Valls, J. (2006). Gestão integral de destinos turísticos sustentáveis. Rio de Janeiro: Editora FGV.

\section{Informações dos autores}

\section{Wagner Fernandes Costa}

Possui Graduação em Turismo e Licenciatura em Geografia (2013), ambas pela Universidade Federal do Rio Grande do Norte (2001 e 2013, respectivamente), especialização em História, Patrimônio Cultural e Turismo pela Universidade Potiguar (2006), mestrado em Turismo (Turismo e Desenvolvimento Regional) pelo Programa de Pós-graduação em Turismo da UFRN (2018). É professor do Ensino Básico, Técnico e Tecnológico do Instituto Federal de Educação Ciência e Tecnologia do Rio Grande do Norte (IFRN) na área de Turismo e Hospitalidade nos níveis superior (presencial) e técnico (presencial e EaD).

E-mail: wagnerfcosta@hotmail.com

ORCID: https://orcid.org/0000-0002-8839-351X

\section{Maria Aparecida Pontes da Fonseca}

Possui graduação em Geografia pela Universidade Estadual Paulista Júlio de Mesquita Filho (1986), mestrado em Geografia (Geografia Humana) pela Universidade de São Paulo (1994), doutorado em Geografia pela Universidade Federal do Rio de Janeiro (2004) e pós doutorado na Universidad Autônoma de Madrid (2016/2017). É professora do Departamento de Geografia da Universidade Federal do Rio Grande do Norte, com dedicação exclusiva, desde 1993. Participa do Programa de Pós Graduação em Geografia e do Programa de Pós Graduação em Turismo, ambos vinculados à Universidade Federal do Rio Grande do Norte. Coordenada o Grupo Interdiciplinar de Pesquisa Turismo e Sociedade.

E-mail: mariapontes@ufrnet.br

ORCID: https://orcid.org/0000-0003-1863-2332 